\title{
Hemophagocytic syndrome after living donor liver transplantation: a case report with a review of the literature
}

\author{
Norifumi Iseda, Tomoharu Yoshizumi, Takeo Toshima*, Akinari Morinaga, Takahiro Tomiyama, Junichi Takahashi, \\ Takashi Motomura, Yohei Mano, Shinji Itoh, Noboru Harada, Toru Ikegami and Yuji Soejima
}

\begin{abstract}
Background: Hemophagocytic syndrome (HPS) is a rare and potentially fatal complication following liver transplantation.

Case presentation: A 63-year-old woman with decompensated liver cirrhosis secondary to hepatitis B virus infection underwent living donor liver transplantation using the right posterior section of her husband's liver (graft volume, $581 \mathrm{~g} ; 56.8 \%$ of the recipient's standard liver volume). She developed small-for-size syndrome on postoperative day (POD) 7, and HPS was diagnosed on POD 12 by bone marrow aspiration (white blood cells,

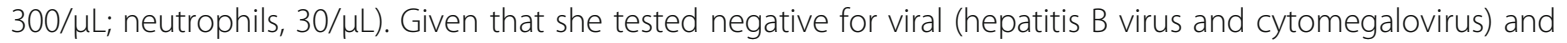
bacterial infections, it was considered likely to be secondary HPS. Steroid pulse therapy was initiated, and her white blood cell count increased to $4290 / \mu \mathrm{L}$ on POD 15, indicating that her peripheral blood leukocytes had improved. There were no surgical complications, but the patient died of prolonged graft dysfunction with bacterial sepsis on POD 14.

Conclusions: We report a rare case of HPS occurring 2 weeks after living donor liver transplantation with a right posterior section graft, diagnosed early via bone marrow aspiration. This clinical course implies an association between HPS and graft dysfunction such as small-for-size syndrome. Further studies of the mechanism of hypercytokinemia-induced HPS are required to confirm the optimal treatment for HPS.
\end{abstract}

Keywords: Hemophagocytic syndrome, Liver transplantation, Small-for-size syndrome

\section{Background}

Hemophagocytic syndrome (HPS) is a rare but potentially fatal complication following liver transplantation [1]. HPS can be difficult to diagnose both clinically and histologically, with delays in diagnosis leading to significant morbidity and mortality. HPS can be either primary, with a genetic etiology, or secondary, associated with malignancies, autoimmune diseases, or infections such as tuberculosis or other viral, bacterial, fungal, or parasitic infections. The precise mechanisms have not been elucidated [2], though some studies have reported a relationship between HPS and small-for-size syndrome (SFSS) with graft dysfunction $[1,3]$.

\footnotetext{
* Correspondence: toshima@surg2.med.kyushu-u.ac.jp Department of Surgery and Science, Graduate School of Medical Sciences, Kyushu University, 3-1-1 Maidashi, Higashi-ku, Fukuoka 812-8582, Japan
}

We present the case of a patient who underwent living donor liver transplantation (LDLT) using a right posterior section graft who subsequently developed HPS and was treated with a combination of intravenous immunoglobulin, granulocyte-colony stimulating factor (G-CSF), calcineurin inhibitor conversion, and steroid pulse therapy.

\section{Case report}

A 63-year-old woman with decompensated liver cirrhosis secondary to hepatitis B virus (HBV) infection was referred as a candidate for LDLT. She had been diagnosed with hepatitis B 20 years before, but it had not been actively treated. She had received best supportive care, but she and her family chose to proceed with LDLT. Laboratory findings before LDLT were as follows: serum total 
bilirubin, $8.4 \mathrm{mg} / \mathrm{dL}$; serum albumin, $2.5 \mathrm{~g} / \mathrm{dL}$; prothrombin time, $40 \%$; platelet count, $84,000 / \mu \mathrm{L}$; and Model for End-stage Liver Disease score, 17. A large amount of ascites, liver atrophy, and collaterals were observed on computed tomography scan. At the time of admission, her urine volume was decreased to $50 \mathrm{~mL} /$ day, and continuous hemodiafiltration treatment was started for renal failure. The predictive risk score [4] was 0.80, which was lower than the score of 1.3 which predicts a poor prognosis, and the risk of postoperative mortality was therefore expected to be high. After obtaining full informed consent from both the donor and the recipient and approval from the Liver Transplantation Committee of Kyushu University, the patient was prepared for LDLT using a right posterior section graft.

The donor was the patient's husband, who was 63 years old and had an identical blood type B. The surgical techniques were carried out as described previously [5]. The graft weight was $581 \mathrm{~g}$, which was equivalent to $56.8 \%$ of the recipient's standard liver volume (graft-recipient weight ratio, $1.12 \%$ ). The hepatic arterial flow in the RHA was $87 \mathrm{~mL} / \mathrm{min}$, and the portal venous flow was $510 \mathrm{~mL} / \mathrm{min}$ after reperfusion. The portal system pressure was $18 \mathrm{mmHg}$ at the end of surgery, and splenectomy was not performed. The anhepatic time, and cold and warm ischemic times were $158 \mathrm{~min}, 92 \mathrm{~min}$, and $49 \mathrm{~min}$, respectively. The surgical time was $10 \mathrm{~h}$, and the estimated blood loss was $4440 \mathrm{~g}$. Ten units of red blood cells, 16 units of frozen plasma, and 40 units of platelets were transfused during surgery.

The post-transplant course is shown in Fig. 1. The patient received post-transplant immunosuppression with tacrolimus, steroid tapering, and mycophenolate mofetil. On postoperative day (POD) 7 , the patient developed SFSS with serum total bilirubin $20.0 \mathrm{mg} / \mathrm{dL}$ and abdominal ascites $2000 \mathrm{~mL} /$ day [6], indicating prolonged cholestasis and intractable ascites [7]. Tests for HBV DNA and cytomegalovirus (CMV) were negative, and repeated blood cultures were also negative until POD 24. There were no signs of abnormal hepatic flow or surgical complications detected by daily Doppler echo until POD 14 and by routine computed tomography scan on POD 7 . There was also no notable elevation of hepatobiliary enzymes, thus ruling out the possibility of graft rejection.

The patient developed a fever above $39^{\circ} \mathrm{C}$ on POD 9, and laboratory findings showed a white blood cell (WBC) count of $1120 / \mu \mathrm{L}$ and a platelet count of 40,000/ $\mu \mathrm{L}$, which fell to $300 / \mu \mathrm{L}$ (neutrophils, 30/ $\mu \mathrm{L}$ ) and $25,000 / \mu \mathrm{L}$, respectively, on POD 11 . She was treated with a combination of G-CSF and intravenous immunoglobulin, but her leukocytopenia/neutropenia failed to improve. Bone marrow aspiration was performed on POD 12, and histology revealed many macrophages and phagocytosis of hematopoietic cells (Fig. 2). The patient was therefore diagnosed with HPS following LDLT. Steroid pulse therapy with $1000 \mathrm{mg} /$ day methylprednisolone was initiated on the same day and continued for 3 days. Her WBC count increased to $4290 / \mu \mathrm{L}$ on POD 15 , suggesting an improvement in her peripheral blood leukocytes. However, the patient developed sepsis with a fever above $39{ }^{\circ} \mathrm{C}$ on POD 24, and blood cultures were positive for Enterococcus faecium and Escherichia coli infections. She recovered rapidly with empiric antibiotic therapy including carbapenem and vancomycin, but her graft dysfunction was prolonged with a consistent serum bilirubin value of around $30 \mathrm{mg} / \mathrm{dL}$, and her renal failure never improved. She also had several episodes of bacterial pneumonia. Splenic artery embolism was performed on POD 84 but failed to improve her graft dysfunction. Regarding immunosuppressive treatment to control infections, mycophenolate mofetil was stopped on POD 8 and not restarted, and the minimum dose of tacrolimus was administered to maintain a trough blood concentration of $3-5 \mathrm{ng} / \mathrm{mL}$. The patient underwent a tracheotomy, and her liver function was expected to improve with long-term management; however, she developed bacterial sepsis and died of liver failure on POD 146.

\section{Discussion}

HPS, also referred to as hemophagocytic lymphohistiocytosis, is a rare and often fatal disease despite treatment [2], characterized by a variety of symptoms including fever, lymphadenopathy, hepatosplenomegaly, jaundice, and skin rash [8]. We report a rare case of a 63-year-old woman who developed HPS 2 weeks after LDLT with a right posterior section graft, who was treated with steroid pulse therapy following an early diagnosis via biopsy. This case may help to shed light on the relationship between HPS and graft dysfunction, including prolonged SFSS.

HPS is defined as a proliferation of phagocytic macrophages in the bone marrow, spleen, or lymph nodes, with clinical findings including fever for $\geq$ 7 days with peaks $\geq 38.5{ }^{\circ} \mathrm{C}$, cytopenia (at least two of three lineages), and splenomegaly [9]. However, this definition is based on infant HPS and may be difficult to apply in adults and patients with various basic diseases such as liver cirrhosis or after LDLT. It is therefore necessary to perform bone marrow aspiration immediately to reach an early diagnosis of HPS in these patients [1]. The laboratory findings in the current patient showed WBC counts of $1120 / \mu \mathrm{L}$ on POD 9 and $300 / \mu \mathrm{L}$ on POD 11. Apart from HPS, other differential diagnoses such as medicine-induced disease, infections such as sepsis, hypersplenism, leukemia, and lack of vitamin B12 were unlikely and bone marrow aspiration on POD 12 showed typical 


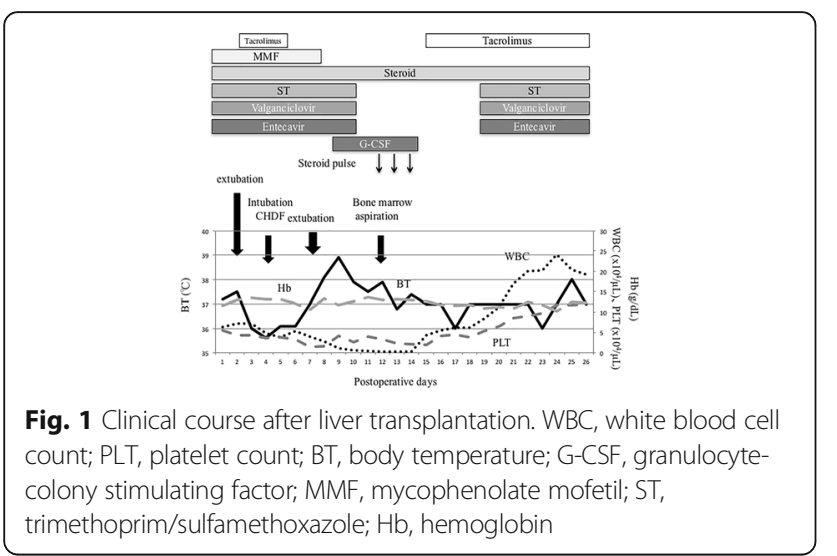

HPS characteristics of phagocytic hematopoietic cells. This rapid diagnosis allowed early treatment with steroid pulse therapy, which contributed to an improvement in the patient's peripheral blood leukocytes.

HPS is a rare complication after liver transplantation with a prognosis for patient survival of $50 \%$ [1, 8]. Fifteen patients, including the present case, have been reported to date (Table 1) [1,3,10-17], only four of whom survived. About a third of secondary HPS cases are associated with virus infection, half with lymphoma, and the remainder with bacterial and fungal infections. Given that HBV DNA and CMV tests on POD 7 were negative and blood cultures were also negative until POD 24, it was considered highly unlikely that the secondary HPS in the current patient was associated with a viral or bacterial infection. The combination of anemia and thrombopenia also added the possibly of thrombotic microangiopathy as a differential diagnosis, but no typical hemolytic anemia was detected in the bone marrow biopsy and there was no sign of encephalopathy. Thrombotic microangiopathy was thus discounted as a possible cause of HPS, and leukopenia was therefore considered the most likely cause. However, liver biopsy after LDLT and measurement of ADAMTS-13 were not performed in the present patient.

In general, patients may develop secondary HPS via hypercytokinemia [18] due to systemic inflammatory response syndrome associated with a viral or bacterial infection. The current LDLT recipient had SFSS, which might have been associated with the donor's older age (63 years) [19]. SFSS can also induce oxidative stress and hypercytokinemia [20].

Based on this hypercytokinemia theory, 10 of the past 15 cases $(66.7 \%)$ were treated with steroids, $10(66.7 \%)$ with intravenous immunoglobulin, and four $(26.7 \%)$ with plasma exchange. The present patient started combination therapy with intravenous immunoglobulin, G-CSF, calcineurin inhibitor conversion, and steroid pulse therapy on POD 12, with subsequent improvement in her peripheral blood leukemia. However, her course was complicated by bacterial sepsis on POD 24. The causal relationship between steroid pulse therapy and sepsis could not be clarified, but the possibility of a septic attack is always present.

In addition, the relationship between SFSS and HPS was not unknown in the present case, and the possible causative effect of SPSS remains speculative. To reduce the risk of HPS, it is necessary to avoid developing viral and bacterial infections and hypercytokinemia, which induce secondary HPS, while the use of elderly donors might also increase the risk of SFSS. However, it may not be possible to avoid these factors in the setting of LDLT. Further studies on the mechanism of hypercytokinemia-induced HPS and more basic studies are needed to confirm the optimal treatment for HPS.

\section{Conclusions}

We report a rare case of HPS that occurred 2 weeks after LDLT using a right posterior section graft, with an early diagnosis made via bone marrow aspiration.

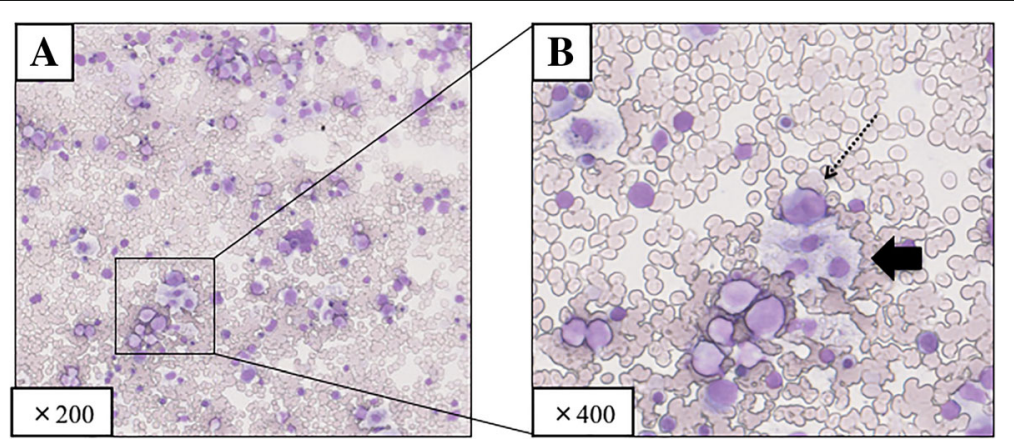

Fig. 2 Bone marrow aspiration revealed many macrophages showing phagocytosis of hematopoietic cells. Dotted arrow shows macrophages phagocytosing neutrophils; thick arrow shows macrophages phagocytosing platelets. a Low-power view, $\times 200 ;$ b high-power view, $\times 400$ 


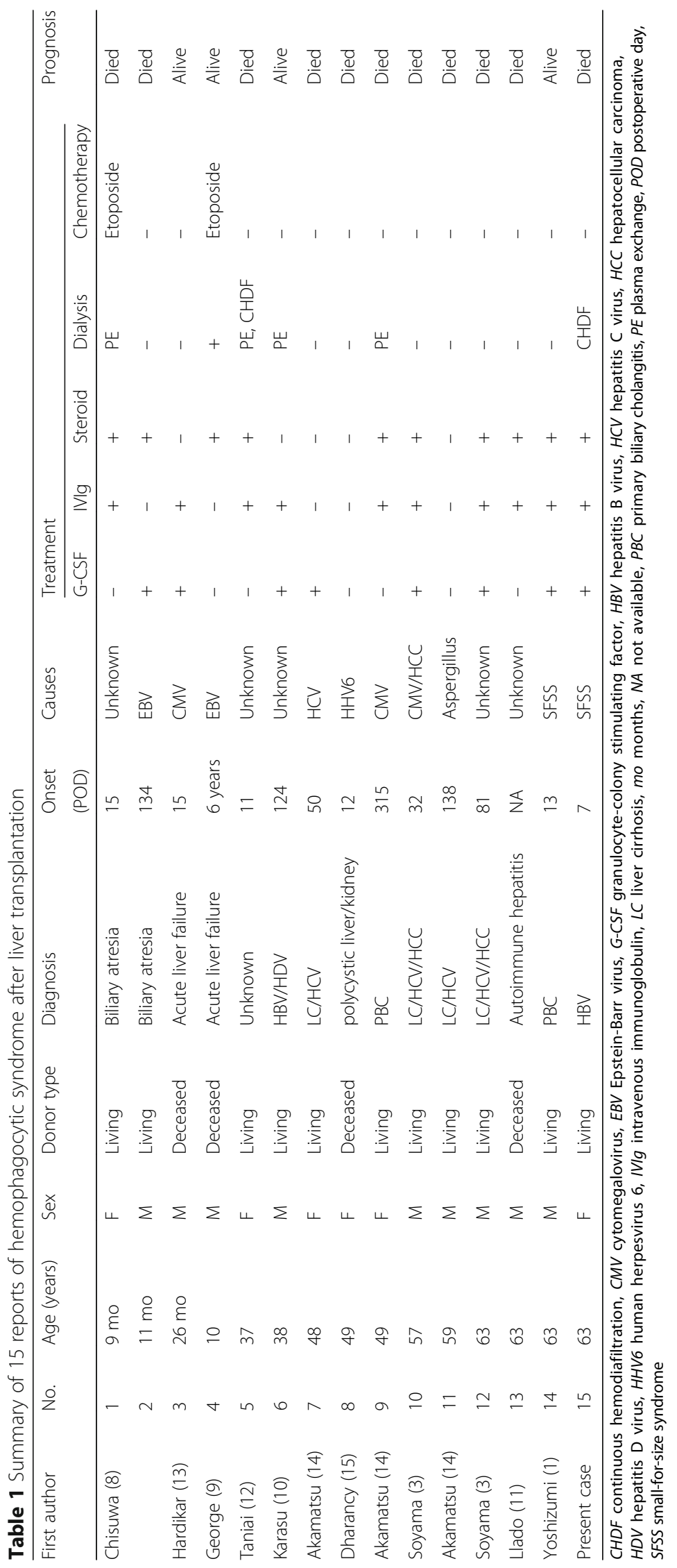


The patient died of liver failure with accompanying bacterial sepsis, but the disease course implied an association between HPS and graft dysfunction, such as SFSS.

\section{Abbreviations}

G-CSF: Granulocyte-colony stimulating factor; HBV: Hepatitis B virus: HPS: Hemophagocytic syndrome; LDLT: Living donor liver transplantation POD: Postoperative day; SFSS: Small-for-size syndrome; WBC: White blood cell

\section{Acknowledgements}

We thank Susan Furness, PhD, from Edanz Group (http://

www.edanzediting.com) for editing a draft of this manuscript.

\section{Funding}

This study was supported by the following grants: the Program for Basic and Clinical Research on Hepatitis from the Japan Agency for Medical Research and Development, AMED (Numbers 17kf02101077h0001 and 17fk0210305h0003) and JSPS KAKENHI, a Grant-in-Aid from the Ministry of Health, Labour and Welfare, Japan (Numbers JP-16K10577 and JP-16K06432). The funding sources had no role in the collection, analysis, or interpretation of the data, or in the decision to submit the article for publication.

\section{Authors' contributions}

$\mathrm{NI}$ participated in the writing of the manuscript and data analysis. TY and TT participated in the research design. AM, TT, and JT participated in data collection. TM, YM, SI, NH, and TI reviewed the manuscript. TY and YS contributed to the discussion and reviewed the manuscript. All authors read and approved the final manuscript.

\section{Ethics approval and consent to participate}

Not applicable

\section{Consent for publication}

The patient consented to the reporting of this case in a scientific publication.

\section{Competing interests}

The authors declare that they have no competing interests.

\section{Publisher's Note}

Springer Nature remains neutral with regard to jurisdictional claims in published maps and institutional affiliations.

Received: 20 April 2018 Accepted: 7 August 2018

Published online: 29 August 2018

References

1. Yoshizumi T, Taketomi A, Kayashima H, Harada N, Uchiyama H, Yamashita Y, Ikegami T, et al. Successful treatment for a patient with hemophagocytic syndrome after a small-for-size graft liver transplantation. Hepatogastroenterology. 2008:55:359-62.

2. Rodriguez-Medina B, Blanes M, Vinaixa C, Aguilera V, Rubin A, Prieto M, Berenguer M. Haemophagocytic syndrome in a liver transplant patient during treatment with Telaprevir. Ann Hepatol. 2013;12:974-8.

3. Soyama A, Eguchi S, Takatsuki M, Hidaka M, Tomonaga T, Yamanouchi K, Miyazaki K, et al. Hemophagocytic syndrome after liver transplantation: report of two cases. Surg Today. 2011;41:1524-30.

4. Yoshizumi T, Taketomi A, Uchiyama H, Harada N, Kayashima H, Yamashita Y, Soejima Y, et al. Graft size, donor age, and patient status are the indicators of early graft function after living donor liver transplantation. Liver Transpl. 2008:14:1007-13.

5. Yoshizumi T, Ikegami T, Kimura K, Uchiyama H, Ikeda T, Shirabe K, Maehara $Y$. Selection of a right posterior sector graft for living donor liver transplantation. Liver Transpl. 2014;20:1089-96.

6. Ikegami T, Shirabe K, Yoshizumi T, Aishima S, Taketomi YA, Soejima Y, Uchiyama $H$, et al. Primary graft dysfunction after living donor liver transplantation is characterized by delayed functional hyperbilirubinemia. Am J Transplant. 2012;12:1886-97.
7. Soejima Y, Taketomi A, Yoshizumi T, Uchiyama H, Harada N, ljichi H, Yonemura $Y$, et al. Feasibility of left lobe living donor liver transplantation between adults: an 8-year, single-center experience of 107 cases. Am J Transplant. 2006;6:1004-11.

8. Sepulveda FE, de Saint Basile G. Hemophagocytic syndrome: primary forms and predisposing conditions. Curr Opin Immunol. 2017:49:20-6.

9. Henter J, Horne A, Arico M, Egeler RM, Filipovich AH, Imashuku S, Ladisch S, et al. HLH-2004: diagnostic and therapeutic guidelines for hemophagocytic lymphohistiocytosis. Pediatr Blood Cancer. 2007;48:124-31.

10. Chisuwa H, Hashikura Y, Nakazawa Y, Kamijo T, Nakazawa K, Nakayama J, Oh-Ishi T, et al. Fatal hemophagocytic syndrome after living-related liver transplantation: a report of two cases. Transplantation. 2001;72:1843-6.

11. George Tl, Jeng M, Berquist W, Cherry AM, Link MP, Arber DA. Epstein-Barr virus-associated peripheral T-cell lymphoma and hemophagocytic syndrome arising after liver transplantation: case report and review of the literature. Pediatr Blood Cancer. 2005;44:270-6.

12. Karasu Z, Kilic M, Cagirgan S, Lebe E, Yilmaz F, Demirbas T, Tokat Y. Hemophagocytic syndrome after living-related liver transplantation. Transplant Proc. 2003;35:1482-4.

13. Llado L, Figueras J, Comi S, Torras J, Serrano T, Castellote J, Jaurrieta E. Haemophagocytic syndrome after liver transplantation in adults. Transpl Int. 2004:17:221-3.

14. Taniai N, Akimaru K, Kawano Y, Mizuguchi Y, Shimizu T, Takahashi T, Mamada Y, et al. Hemophagocytic syndrome after living-donor liver transplantation for fulminant liver failure: a case report. Hepatogastroenterology. 2005:52:923-6.

15. Hardikar W, Pang K, Al-Hebbi H, Curtis N, Couper R. Successful treatment of cytomegalovirus-associated haemophagocytic syndrome following paediatric orthotopic liver transplantation. J Paediatr Child Health. 2006:42:389-91.

16. Akamatsu N, Sugawara Y, Tamura S, Matsui $Y$, Hasegawa K, Imamura H, Kokudo N, et al. Hemophagocytic syndrome after adult-to-adult living donor liver transplantation. Transplant Proc. 2006:38:1425-8.

17. Dharancy S, Crombe V, Copin MC, Boleslawski E, Bocket L, Declerck N Canva V, et al. Fatal hemophagocytic syndrome related to human herpesvirus-6 reinfection following liver transplantation: a case report. Transplant Proc. 2008:40:3791-3.

18. Weaver LK, Behrens EM. Weathering the storm: improving therapeutic interventions for cytokine storm syndromes by targeting disease pathogenesis. Curr Treatm Opt Rheumatol. 2017;3:33-48

19. Sanefuji K, Iguchi T, Ueda S, Nagata S, Sugimachi K, Ikegami T, Gion T, et al. New prediction factors of small-for-size syndrome in living donor adult liver transplantation for chronic liver disease. Transpl Int. 2010;23:350-7.

20. Cui YY, Qian JM, Yao AH, Ma ZY, Qian XF, Zha XM, Zhao Y, et al. SOD mimetic improves the function, growth, and survival of small-size liver grafts after transplantation in rats. Transplantation. 2012;94:687-94.

\section{Submit your manuscript to a SpringerOpen ${ }^{\odot}$ journal and benefit from:}

- Convenient online submission

- Rigorous peer review

- Open access: articles freely available online

- High visibility within the field

- Retaining the copyright to your article

Submit your next manuscript at $>$ springeropen.com 